\title{
No spatial learning impairment following exposure to inescapable shock
}

\author{
DONALD A. WARREN, CARL A. CASTRO, JERRY W. RUDY, and STEVEN F. MAIER \\ University of Colorado, Boulder, Colorado
}

\begin{abstract}
Uncontrollable stressors produce changes both in hippocampal physiology and in cognitive performance. It has been suggested that some of the cognitive effects of uncontrollable shock may be mediated by disturbances in hippocampal processes. We evaluated the prediction that inescapable shock should produce a learning deficit in a task known to be particularly sensitive to disruption in hippocampal function-the Morris water-maze spatial-learning task. Exposure to a single session of inescapable shock of the type typically employed in learned helplessness experiments produced no apparent effect on performance regardless of whether shock was given $30 \mathrm{~min}$ or $6 \mathrm{~h}$ prior to water-maze training or whether animals were tested at retention intervals of $0,1,4$, or $24 \mathrm{~h}$ following training. Similarly, no effect of inescapable shock was observed when shock treatment and water-maze training were distributed over three daily sessions. These results are inconsistent with the hypothesis that the effects of inescapable shock on cognitive performance result from disturbances in hippocampal function.
\end{abstract}

Exposure to inescapable shock produces a variety of behavioral and physiological consequences. Among these are deficits in the ability to learn a novel response to escape or avoid footshock (Maier, Albin, \& Testa, 1973; Overmier \& Seligman, 1967) or to produce food reward (Rosellini, 1978). Physiological changes include an opioid hypoalgesic response to subsequent shock (Drugan \& Maier, 1983), changes in neurochemical metabolism in specific brain regions (Anisman \& Sklar, 1979; Petty \& Sherman, 1981; Weiss et al., 1981) and disturbances in hippocampal neuronal plasticity (Foy, Stanton, Levine, \& Thompson, 1987; Shors, Steib, Levine, \& Thompson, 1989). The degree to which the animal is permitted to exert control over shock appears to be a critical modulator of these various effects. The equivalent pattern and the amount of escapable shock usually do not have such dramatic impact. Because shock must be uncontrollable to produce these behavioral and physiological changes, they have been collectively termed learned helplessness effects.

Many investigators have been interested in the cognitive effects of uncontrollable shock. Cognitive changes are evidenced by deficient performance in response-choice or position-discrimination tasks (Jackson, Alexander, \& Maier, 1980; Lee \& Maier, 1988; Minor, Jackson, \& Maier, 1984; Rosellini, DeCola, \& Shapiro, 1982), as well as enhanced performance in tasks that assess either visual-cue discrimination (Lee \& Maier, 1988) or sensitivity to changes in response-reinforcer contingencies (Rosellini, DeCola, Plonsky, Warren, \& Stilman, 1984;

This research was supported by National Science Foundation Grant BNS 88-08840 to Steven F. Maier. We thank Michael Kanda for his assistance. Correspondence concerning this article should be sent to Steven F. Maier, Department of Psychology, Campus Box 345, University of Colorado, Boulder, CO 80309.
Warren, Rosellini, Plonsky, \& DeCola, 1985). Furthermore, compared with control animals, the performance of animals given inescapable shock is more disrupted by exteroceptive "distractor" stimuli presented randomly during a learning task (Minor et al., 1984) but is enhanced if such stimuli are presented as feedback to the animals' responses (Maier, Jackson, \& Tomie, 1987). This finding suggests that inescapable shock produces a shift in selective attention to exteroceptive cues.

Although it is clear that inescapable shock can produce dramatic effects in both behavior and physiology, the physiological mechanisms underlying the behavioral changes are not well understood. However, several lines of evidence suggest that the hippocampus may play an important role in mediating some effects. First, Sherman and Petty (1980) showed that microinjection of gammaaminobutyric acid (GABA) into the hippocampus prior to inescapable shock could block the development of learned helplessness, as assessed in a shock-escape task. Later, Petty and Sherman (1981) reported that animals given inescapable shock show a decrease in GABA release in the hippocampus and that pharmacological treatments known to protect against learned helplessness (Sherman, Allers, Petty, \& Henn, 1979) were observed to increase hippocampal GABA levels. Finally, it has been reported that shock exposure suppresses induction of long-term potentiation (LTP) in the hippocampus (Foy, Foy, Levine, \& Thompson, 1990; Foy et al., 1987) and that inescapable shock exerts a greater suppressive effect than does escapable shock (Shors et al., 1989). Results of lesion studies, however, have been equivocal. Hippocampectomy has been reported to enhance the escape-learning impairment produced by exposure to uncontrollable shock (Elmes, Jarrard, \& Swart, 1975). Conversely, transection of the major efferent pathway from the hippocampus 
reportedly blocks development of the escape deficit (Leshner \& Segal, 1979).

On the basis of findings that indicate that hippocampal processes are changed by exposure to inescapable shock, it has been suggested that disturbances in hippocampal function may constitute a mechanism by which inescapable shock produces cognitive changes (Foy et al., 1990; Foy et al., 1987). The purpose of the present research was to evaluate this hypothesis. Our strategy was to determine whether exposure to inescapable shock affects performance on a task that is known to be especially sensitive to disturbances in hippocampal functioning. If the behavioral effects of inescapable shock are mediated by altered hippocampal processes, then a task that is known to be sensitive to changes in hippocampal function also should be sensitive to the effects of inescapable shock. To implement this strategy, we chose to examine the effects of inescapable shock on place learning in the Morris (1981) water-maze task. A place-learning task was chosen because it is well established that performance on such tasks is highly sensitive to treatments that alter hippocampal function (Barnes, 1988; McNaughton, Barnes, Rao, Baldwin, \& Rasmussen, 1986; Morris, 1989; Morris, Garrud, Rawlins, \& O'Keefe, 1982; O'Keefe \& Nadel, 1978; Sutherland \& Rudy, 1988; Sutherland, Wishaw, $\&$ Kolb, 1983). Contrary to the hypothesis that inescapable shock exerts its cognitive effects by altering hippocampal function, the performance of animals that had been given inescapable shock was indistinguishable from that of nonshocked control animals across a variety of training and testing conditions.

\section{EXPERIMENTS 1a AND 1b}

In these experiments, place learning was examined at two temporal intervals following a single session of inescapable shock. In Experiment la, training commenced 30 min after the shock session; in Experiment 1b, it commenced $6 \mathrm{~h}$ after the shock session.

\section{Method}

Subjects. Experiments $1 \mathrm{a}$ and $\mathrm{lb}$ each employed 16 experimentally naive male Holtzman rats. Animals were between 80 and 100 days of age and were housed singly in standard wire suspension cages, with food and water available ad lib. Experimental events occurred during the light portion of a 12:12 light:dark cycle.

Apparatus. Inescapable shock was administered in four clear Plexiglas restraint tubes measuring $25.3 \mathrm{~cm}$ long $\times 7.0 \mathrm{~cm}$ in diameter. The front wall was adjustable to accommodate animals of varying sizes. The animal's tail extended through a hole cut in the rear wall and was taped to a Plexiglas rod. Unscrambled shocks were delivered by units modeled after the Grason-Stadler Model 700 through fuse-clip electrodes taped to the tail and augmented with electrode paste.

Water-maze testing was conducted in a circular pool $100 \mathrm{~cm}$ in diameter and filled with water to a level approximately $11.0 \mathrm{~cm}$ from the rim. The inner walls of the pool were painted white. The water was maintained at $23^{\circ} \mathrm{C}( \pm 1)$ and was made opaque by the addition of nontoxic white-powder paint. The room in which the pool was located contained a variety of objects that were visible from inside the pool and that could serve as distal navigational cues. During training trials, an escape platform, constructed of clear Plexi- glas and measuring $15.0 \mathrm{~cm}$ in diameter, was positioned approximately $1.0 \mathrm{~cm}$ below the surface of the water in the center of the north quadrant of the pool. The animals' performance was recorded by a tracking system with an Apple II microcomputer and a video camera located directly above the pool. This pool, tracking system, and configuration of cues have been employed previously to demonstrate place-learning deficits in animals with hippocampal damage (Sutherland \& Rudy, 1988).

Procedure. In both Experiments $1 \mathrm{a}$ and $1 \mathrm{~b}$, animals were randomly assigned to two groups $(n=8)$. Animals in Group $S$ received 100 inescapable tailshocks of 1.0-mA intensity and 5-sec duration presented on a variable-time $60-\mathrm{sec}$ schedule (range $=15-120 \mathrm{sec}$ ). Animals in Group $\mathrm{N}$ were left undisturbed in their home cages during this time.

Following shock treatment, a permanent marker was used to place a small but visible spot of dark ink onto the back of the animal's head. This was done in order to provide a high-contrast image that could be detected by the system employed to track the animal's swim path in the water maze. Either 30 min (Experiment 1a) or $6 \mathrm{~h}$ (Experiment $1 \mathrm{~b}$ ) after shock, all animals were trained to locate the hidden escape platform in the water maze. First, each animal was placed several times into the pool with its forepaws contacting the platform surface, thus training the animal to climb onto the platform. Eighteen training trials were then given. Trials were initiated by gently placing the animal into the water at varying starting locations along the wall, thus encouraging an escape strategy employing spatial cues (see Morris, 1981). Latency to find and climb onto the platform located in the "training" quadrant was recorded. If the animal failed to escape within $60 \mathrm{sec}$, it was placed onto the platform and a latency of $60 \mathrm{sec}$ was recorded. Upon either climbing onto the platform or being placed upon it, the animal was permitted to remain on the platform for approximately $10 \mathrm{sec}$. Following this, either another trial was initiated or the animal was placed into a nearby holding cage pending the next block of trials. Training proceded in blocks of two trials, with an interval of approximately $5 \mathrm{~min}$ interposed between blocks.

Within 5 min following the 18th training trial, a probe trial was conducted. Here, the platform was removed from the pool, and the animal was released into the south quadrant (opposite the training quadrant) and permitted to swim freely for $60 \mathrm{sec}$. The amount of time spent swimming in each of the four pool quadrants was recorded. In addition, the number of times the animal crossed over either the location formerly occupied by the platform or the equivalent locations in the three remaining quadrants was recorded. Watermaze training and probe trials were conducted by an experimenter who was blind to the animals' group membership.

\section{Results and Discussion}

Quadrant swim time during the probe trials was converted to the percentage of 60 -sec total trial time. Escape latencies, the percentage quadrant swim time, and platform-crossing measures were analyzed by mixeddesign analyses of variance (ANOVA). Follow-up contrasts compared swim time in the training quadrant with that for the nontraining quadrants combined. In all experiments, conclusions reached on the basis of the platform-crossing data were essentially identical to those reached on the basis of the percentage quadrant swimtime measure. Therefore, only the quadrant swim-time results are presented.

Escape latencies: Experiment la. Animals in both groups learned to quickly locate the escape platform with 18 training trials (see Figure 1A). Furthermore, latencies in Group $\mathrm{S}$ were shorter than those in Group $\mathrm{N}$ on several trial blocks. An ANOVA revealed significant main ef- 
(A)

30 MIN AFTER STRESS

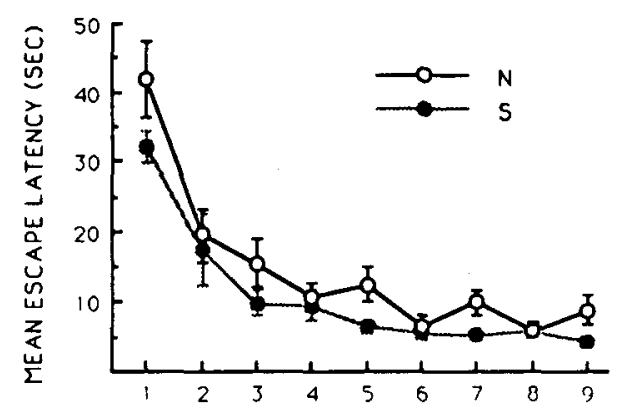

(B)

6 HR AFTER STRESS

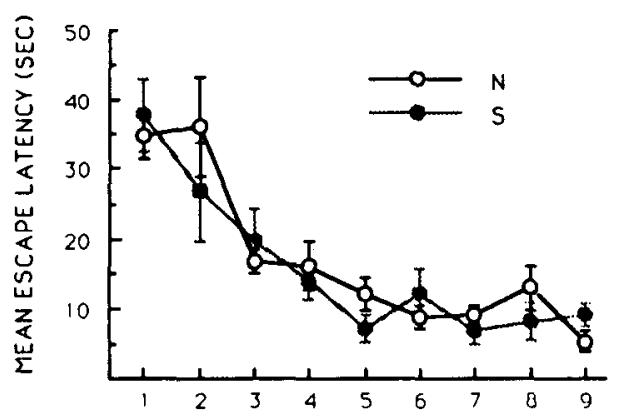

BLOCKS OF TWO TRIALS

Figure 1. Mean latencies to locate hidden escape platform (+ standard error of the mean) across blocks of two trials in animals given no shock (N) and in those given uncontrollable shock (S) in Experiments $1 \mathrm{a}$ and $1 \mathrm{~b}$. Group $\mathrm{S}$ animals were given inescapable shock either 30 min before water-maze training (Panel A) or $6 \mathrm{~h}$ earlier (Panel B).

fects of both groups and blocks of 2 trials $[F(1,14)=$ $8.834, p=.010$, and $F(8,112)=30.917, p<.001$, respectively], with no significant group $\times$ blocks interaction.

Escape latencies: Experiment $\mathrm{lb}$. Again, animals in both groups successfully learned to locate the escape platform with 18 training trials (see Figure 1B), and there were no differences between the groups. This pattern resulted in a statistically significant main effect of trial blocks $[F(8,112)=16.607, p<.001]$, with no significant effect of group or group $\times$ blocks interaction.

Quadrant search: Experiment la. As expected, animals spent a greater percentage of probe-trial time in the training quadrant than they spent in any of the three nontraining quadrants. Furthermore, as shown in Figure 2A, there was no apparent effect of inescapable shock. Performance in Groups $\mathbf{N}$ and $\mathbf{S}$ was virtually indistinguishable. This pattern was reflected in a statistically significant effect of quadrant $[F(3,42)=31.805, p<.001]$, with no signifi- cant group $\times$ quadrant interaction $(F<1.0)$. Contrasts revealed that in both nonshocked and shocked animals the percentage time in the training quadrant was significantly greater than that for the nontraining quadrants in both nonshocked and shocked animals $[F(1,42)=23.49$, $p<.001$, and $F(1,42)=22.18, p<.001$, respectively].

Quadrant search: Experiment $1 b$. Again, during the probe trial, animals spent a greater percentage of time in the training quadrant than in any of the three nontraining quadrants. Furthermore, as shown in Figure 2B, performance in Groups $\mathbf{N}$ and $\mathbf{S}$ was virtually indistinguishable. This pattern resulted in a statistically significant effect of quadrant $[F(3,42)=15.292, p<.001]$, with no significant group $\times$ quadrant interaction $(F<1.0)$. Again, contrasts revealed that in both nonshocked and shocked animals the percentage time in the training quadrant was significantly greater than that for the nontraining quadrants $[F(1,42)=22.44, p<.001$, and $F(1,42)=17.57$, $p<.001$, respectively].

Thus, in two measures of spatial learning in the Morris water maze (i.e., escape latencies and quadrant search time), inescapable shock produced no observable impairment. This was true regardless of whether shock treatment was given $30 \mathrm{~min}$ or $6 \mathrm{~h}$ prior to water-escape training.

\section{EXPERIMENT 2}

The results of Experiments la and lb suggest that uncontrollable shock does not exert an observable impact on the animal's ability to learn a spatial-navigation task. However, before accepting the null hypothesis, we must entertain the notion that our test parameters may not have been optimal for revealing what may be a subtle effect of inescapable shock. At least two features of our test may have masked the effect of inescapable shock. First, because the escape platform was in the same quadrant of the pool for all animals, it is possible that unconditioned position biases contributed to the pattern of quadrant preferences observed on the probe trial. For example, it has been reported that stress produces an enhanced tendency to favor the more highly illuminated regions of a water-filled arena (Prince, Collins, \& Anisman, 1986; Szostak \& Anisman, 1985). Any similar unlearned tendencies to favor uncontrolled stimulus characteristics peculiar to the training quadrant in Experiments la and $1 \mathrm{~b}$ could conceivably mask a spatial-learning impairment. Therefore, in Experiment 2, training-quadrant designation was balanced such that the escape platform was placed in the north quadrant for half the animals in each group, whereas for the remaining half the platform was located in the south quadrant. Such a procedure effectively controls for unconditioned location biases.

Second, it is possible that inescapable shock has no effect on the acquisition of place learning but does influence retention processes that enable place information to be remembered. So in this experiment the retention interval between escape training and the probe trial was varied 


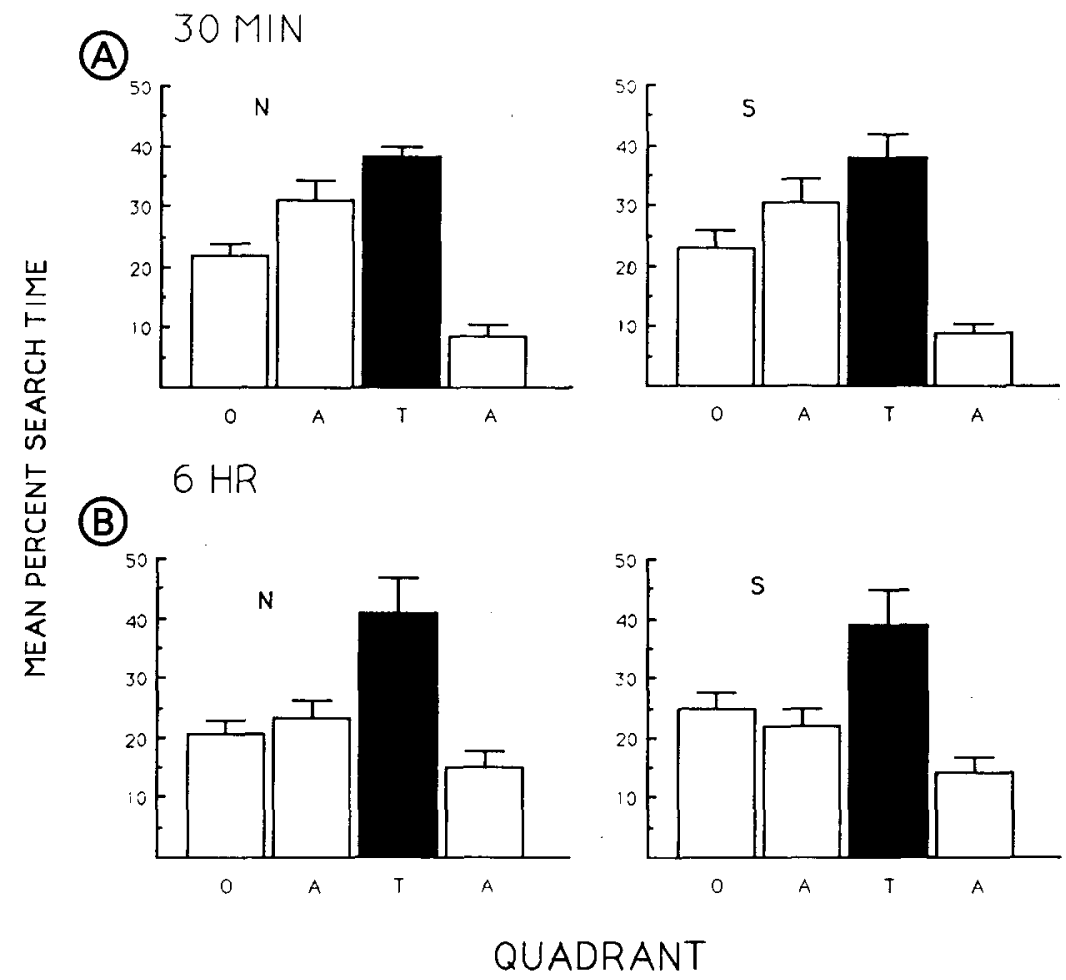

Figure 2. Mean percentage of probe-trial time (+ standard error of the mean) spent in the four pool quadrants in animals given no shock $(N)$ and in those given uncontrollable shock $(S)$ in Experiments $1 \mathrm{a}$ and $1 \mathrm{~b}$. Group $S$ animals were given inescapable shock either 30 min before water-maze training (Panel A) or 6 h earlier (Panel B). The probe trial was conducted immediately following water-escape training. $T=$ training quadrant, $A=$ adjacent quadrants, $O=$ opposite quadrant.

in an attempt to provide a more sensitive assay of the effects of inescapable shock. Animals were probed either immediately ( $5 \mathrm{~min}), 1,4$, or $24 \mathrm{~h}$ after the last escapetraining trial.

\section{Method}

Subjects. Experiment 2 used 64 experimentally naive rats of the same age, sex, and strain as those used in Experiments 1a and $1 \mathrm{~b}$. All were housed in groups of 3, with food and water available ad lib.

Apparatus. Inescapable shock was administered with the use of the same equipment as that used in Experiments 1a and 1b. Watermaze training and testing were conducted with the use of a pool housed in a different room than that used in Experiments 1a and $1 \mathrm{~b}$, and probe-trial performance was recorded on videotape and scored by a human observer. In all other respects, the testing apparatus was identical to that used in Experiments $1 \mathrm{a}$ and $\mathbf{l b}$.

Procedure. Shock treatment was identical to that given in Experiments la and $1 b$, with the exception that shock intensity was increased to $1.3 \mathrm{~mA}$. As in Experiment 1a, animals were given 18 escape-training trials in the pool within 30 min after shock. For half of the animals in each experimental group, the north quadrant was designated as the training quadrant. For the remaining half, the south quadrant served as the training quadrant. Following the final escape-training trial, animals in both the shock and nonshock conditions received an interval of either $5 \min (0 \mathrm{~h}), 1,4$, or $24 \mathrm{~h}$ preceding the probe trial. Animals in the 0 -h condition spent this interval in a temporary holding cage, whereas those in the 1-, 4-, and $24-\mathrm{h}$ conditions spent the retention interval in their home cages. Thus, this experiment employed eight groups $(n=8)$ distinguished on the basis of shock treatment combined factorially with varying retention intervals.

\section{Results and Discussion}

Escape latencies. As shown in Figure 3, both shocked and nonshocked animals learned to quickly locate the escape platform. Furthermore, unlike the results of Experiment 1a, in which escape latencies of shocked animals were shorter than those of nonshocked controls, latencies of shocked and nonshocked animals in this experiment were equivalent. An ANOVA revealed a significant effect of trial blocks $[F(8,496)=65.631, p<.001]$, with no significant effect of group or group $\times$ blocks interaction.

Quadrant search. Figure 4 shows the quadrant search patterns during the probe trial in shocked and nonshocked animals tested either $0,1,4$, or $24 \mathrm{~h}$ after water-escape training. As in Experiments 1a and 1b, shocked and nonshocked animals displayed a bias for the training quadrant when tested immediately following training. This pattern was also observed in animals given the probe trial $1 \mathrm{~h}$ after training and was evident in considerably weaker form in those given the probe trial $4 \mathrm{~h}$ after training. Animals tested $24 \mathrm{~h}$ after training did not appear to favor the training quadrant at all. More importantly, performance levels in shocked and nonshocked animals were 


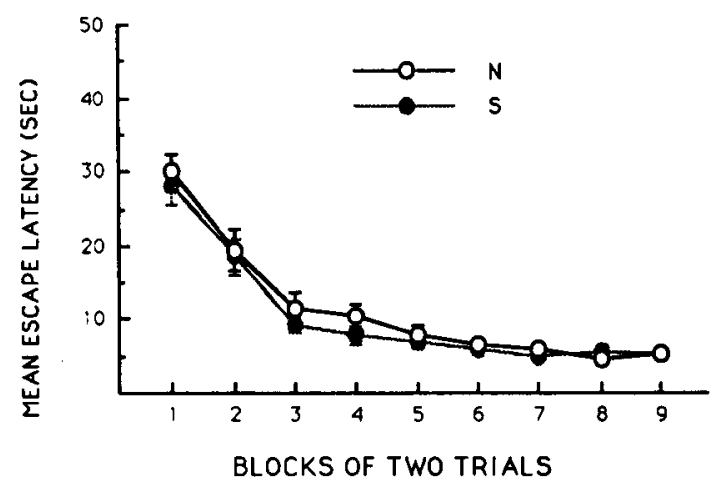

Figure 3. Mean latencies to locate hidden escape platform (+ standard error of the mean) across blocks of two trials in animals given no shock $(N)$ and in those given uncontrollable shock (S) $30 \mathrm{~min}$ before water-escape training.

equivalent at all retention times. This pattern resulted in a significant effect of quadrant $[F(3,168)=39.645$, $p<.001]$ and a significant time $\times$ quadrant interaction $[F(9,168)=5.337, p<.001]$ but no significant shock $\times$ quadrant or shock $\times$ time $\times$ quadrant interaction $(F \mathrm{~s}<1.0)$. Contrasts showed that, for both shocked and nonshocked animals, significantly more time was spent in the training quadrant than in the nontraining quadrants at the $0-, 1-$, and $4-h$ retention times $[F \mathrm{~s}(1,168)>5.07$, $p s<.024]$ but not at the 24-h time point ( $p$ s $>.201$ ).

These results show that animals that receive inescapable shock both acquire and retain place information as well as nonshocked animals. Thus, in spite of our altering the task parameters to increase its sensitivity, inescapable shock still exerted no detectable effect.

\section{EXPERIMENT 3}

The hypothesis that inescapable shock affects cognitive performance by means of alteration in hippocampal function predicts that a known hippocampus-dependent placelearning task should be particularly sensitive to the effects of inescapable shock. The results of Experiments $1 \mathrm{a}, 1 \mathrm{~b}$, and 2 clearly are contrary to this prediction. Yet, it must be recognized that this hypothesis is based, in part, on the results of experiments that have often employed treatment and test procedures that differ somewhat from those commonly used in learned-helplessness experiments. For example, although 30 shocks per session administered in either a single session (Foy et al., 1990; Foy et al., 1987) or over multiple sessions (Shors et al., 1989) were shown to be effective in suppressing hippocampal LTP, 80-100 shocks are typically administered in a single session to produce learned-helplessness effects. Similarly, learning tasks that have been shown to be sensitive to disruption of hippocampal function often involve multiple training sessions and test the animal's ability to retain information for periods longer than several hours (e.g., McNaughton et al., 1986; Morris et al., 1982). In the previous experiments, animals received only a single 18trial training session and only retained place information for $4 \mathrm{~h}$. When the retention interval was $24 \mathrm{~h}$, neither the shocked nor the control animals selectively searched the training quadrant. Perhaps an effect of inescapable shock will be observed only with parameters that promote longterm retention of place learning.

With these considerations in mind, we altered the parameters of the experiment in several ways: (1) only 30 shock trials were administered before each placelearning session, (2) multiple place-learning sessions were administered, and (3) all animals received a probe trial $24 \mathrm{~h}$ after the last training session.

\section{Method}

Subjects and Apparatus. Experiment 3 used 16 experimentally naive male rats of the same age, strain, and housing conditions as those used in Experiment 2. Inescapable shock and water-maze training were conducted with the use of the same apparatus as that used in Experiment 2.

Procedure. Shock-treatment procedures were identical to those of Experiments 1a, 1b, and 2, with the exception that shock intensity (1.0 mA) and the number of shocks (30) delivered in each session more closely matched the intensity and number of shocks reported to produce suppression of hippocampal LTP (Foy et al., 1990; Foy et al., 1987; Shors et al., 1989). Animals in Group S received three daily shock sessions while those in Group $\mathrm{N}$ remained undisturbed in their home cages.
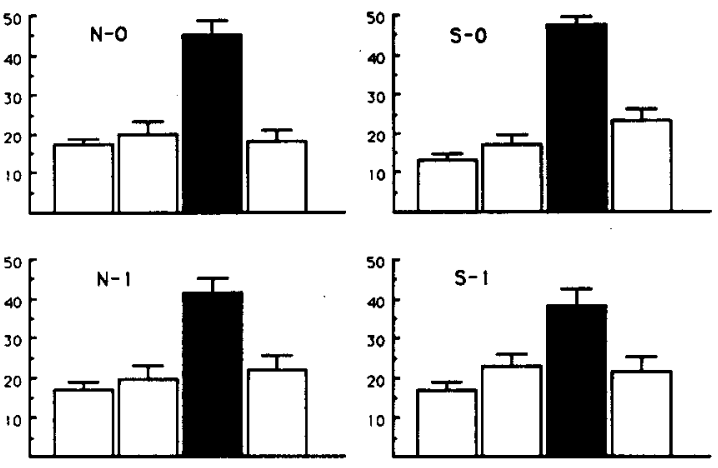

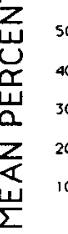
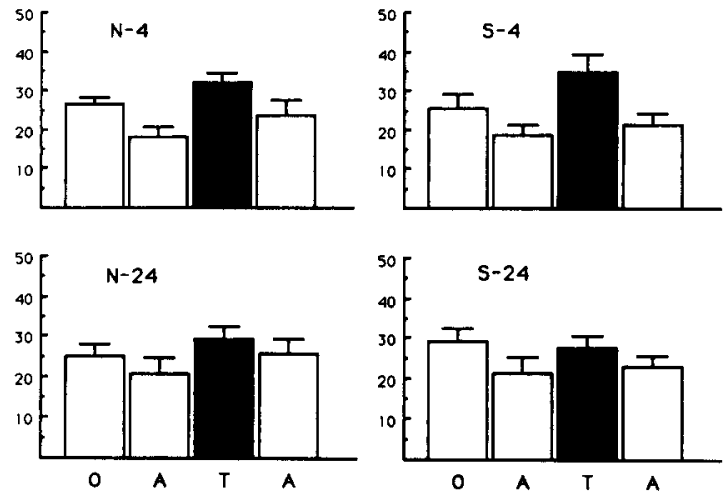

\section{QUADRANT}

Figure 4. Mean percentage of probe-trial time (+ standard error of the mean) spent in the four pool quadrants in animals given either no shock or uncontrollable shock $30 \mathrm{~min}$ prior to water-escape training. The probe trial was conducted either $0,1,4$, or $24 \mathrm{~h}$ after training. $T=$ training quadrant, $A=$ adjacent quadrants, $O=$ opposite quadrant. 


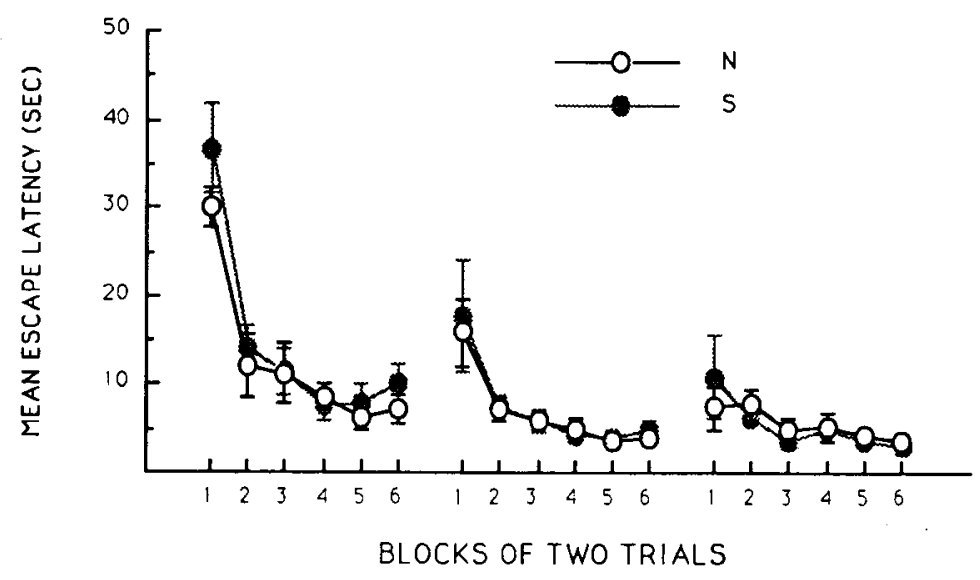

Figure 5. Mean latencies to locate hidden escape platform ( + standard error of the mean) across blocks of two trials for 3 days in animals given no shock (N) and in those given 30 uncontrollable shocks (S) 30 min before each water-escape training session.
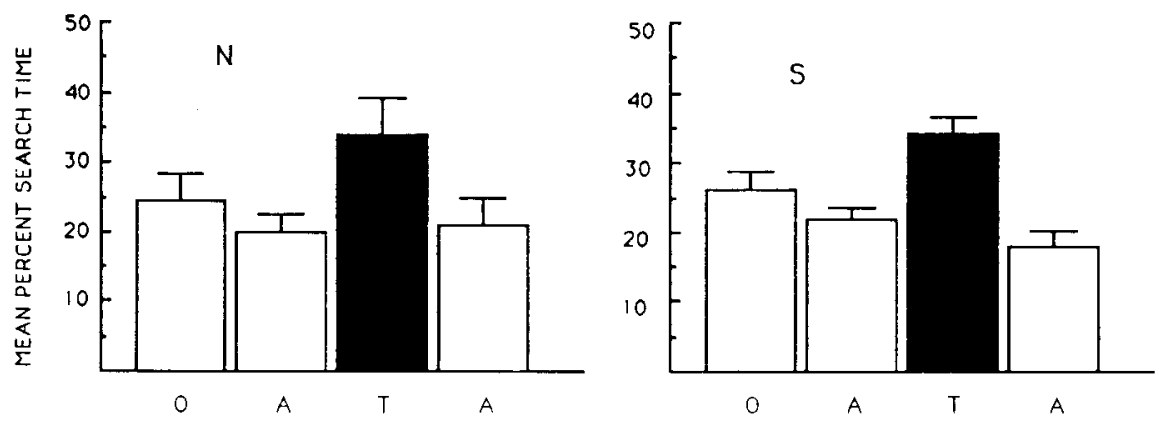

\section{QUADRANT}

Figure 6. Mean percentage of probe-trial time (+ standard error of the mean) spent in the four pool quadrants in animals given either no shock or uncontrollable shock 30 min prior to each of three daily water-escape training sessions. The probe trial was conducted $24 \mathrm{~h}$ after the last training session. $\mathbf{T}=$ training quadrant, $\mathbf{A}=$ adjacent quadrants, $\mathbf{O}=$ opposite quadrant.

Water-maze training procedures were identical to those in Experiment 2 , with the exception that 12 training trials were given within $30 \mathrm{~min}$ after each shock-treatment session. A single probe trial was conducted $24 \mathrm{~h}$ after the last training session.

\section{Results and Discussion}

Escape latencies. Both shocked and nonshocked animals learned to quickly locate the escape platform (see Figure 5). An ANOVA revealed a significant effect of trial blocks $[F(17,238)=7.15, p<.001]$, with no significant effect of group or group $\times$ blocks interaction.

Quadrant search. Although the retention interval was $24 \mathrm{~h}$, both shocked and nonshocked animals spent more time swimming in the training quadrant than in any of the nontraining quadrants (see Figure 6). Furthermore, the performance of shocked animals was indistinguishable from that of nonshocked animals. An ANOVA revealed a significant effect of quadrant $[F(3,42)=6.210$, $p<.001]$ but no significant group $\times$ quadrant interaction $(F<1.0)$. Contrasts revealed that in both nonshocked and shocked animals the percentage time in the training quadrant was significantly greater than that for the nontraining quadrants $[F(1,42)=7.82, p=.008$, and $F(1,42)=8.13, p=.007$, respectively $]$.

The results of Experiment 3 replicate those of Experiments $1 \mathrm{a}, 1 \mathrm{~b}$, and 2 in that the performance of animals given inescapable shock was again indistinguishable from that of nonshocked animals. Furthermore, the present results extend these findings by showing that (1) long-term spatial-memory formation is relatively invulnerable to disruption by inescapable shock, as is the formation of shortterm spatial memory as observed in Experiments 1a, 1b, and 2, and (2) this task is insensitive to the impact of a stressor treatment similar to that which results in suppression of hippocampal LTP (Foy et al., 1990; Foy et al., 1987; Shors et al., 1989). 


\section{GENERAL DISCUSSION}

In four experiments, inescapable shock had no effect on either the acquisition or the retention of place learning. This equivalence between shocked and nonshocked animals was observed regardless of whether water-maze training was conducted $30 \mathrm{~min}$ after shock (Experiment $1 \mathrm{a})$ or $6 \mathrm{~h}$ after shock (Experiment $1 \mathrm{~b}$ ). Experiment 2 showed that the performance of animals given a shock session 30 min prior to water-escape training was indistinguishable from that of nonshocked animals at several retention intervals after the training session. Furthermore, in Experiment 3, no effect of inescapable shock was observed when shock treatment and water-maze training were distributed over multiple daily sessions, and spatial memory persisted for up to $24 \mathrm{~h}$ after the final training session. These results strongly suggest that inescapable shock treatments, which are known to produce dramatic effects in a wide variety of other learning tasks (e.g., Lee \& Maier, 1988; Maier et al., 1973; Rosellini, 1978) and which reportedly alter hippocampal physiology (Foy et al., 1990; Foy et al., 1987; Shors et al., 1989), produce no deficit in a spatial-learning task.

Given that inescapable shock failed to influence watermaze performance under the conditions tested, one may question whether the shock treatment we employed was sufficient to produce a stress response, as evidenced by standard neuroendocrine and behavioral measures. We took no systematic measures of stress in the present experiments. However, results obtained previously, in both this laboratory and others, provide abundant evidence of stress resulting from shock treatment that is similar or identical to that used in this study. In addition to the wellknown learning deficits, animals given inescapable shock show intense fear of cues associated with shock (Maier, 1990; Warren, Rosellini, \& Maier, 1989; Williams, 1987), increased central catecholamine utilization (Woodmansee, Desan, Silbert, Smock, \& Maier, 1988), and large increases in plasma ACTH and corticosterone concentrations (Maier, Ryan, Barksdale, \& Kalin, 1986). Thus, there is little doubt that the shock treatment employed in this study is sufficient to elicit a robust stress response.

However, because we did not monitor neuroendocrine indexes of stress, we are unable to evaluate the stressfulness of water-maze testing. It might be argued that the swimming paradigm was itself so stressful that both shocked and nonshocked animals may have reached a "stress ceiling"' that precluded observation of the effects of shock treatment. Although this is a logical possibility, it appears unlikely, in view of the fact that the effects of inescapable shock are evident in a variety of other tests that are themselves stressful, such as those that employ exposure to additional shock (Jackson et al., 1980; Maier et al., 1973; Minor et al., 1984) or aggressive conspecifics (Williams \& Lierle, 1986). Furthermore, it has been shown previously in this laboratory that effects of inescapable shock can indeed be observed in a swimming paradigm in which cognitive processes other than spatial learning are assessed (Lee \& Maier, 1988). Therefore, it is unlikely that the stress of swimming is responsible for the observed equivalence between shocked and nonshocked animals in these experiments.

It has been suggested that stress may exert some of its effects on cognition by means of disturbances in hippocampal physiology, notably those processes governing LTP (Foy et al., 1987; Shors et al., 1989) or neurochemical metabolism (e.g., Petty \& Sherman, 1981). Although this hypothesis has some appeal, it is instructive to note that impaired hippocampal functioning does not produce deficits in all learning and memory tasks (see, for reviews, Barnes, 1988; Sutherland \& Rudy, 1989). Indeed, performance on some tasks that are influenced by inescapable shock (e.g., simple position and brightness discriminations) is unaffected by hippocampal damage. These considerations alone are not inconsistent with the hypothesis that inescapable shock exerts some of its effects by means of alteration in hippocampal functioning. That is, the range of tasks influenced by inescapable shock may be so broad as to include both those that are hippocampusdependent and others that are not. However, this possibility is rendered somewhat untenable by our finding that inescapable shock does not impair performance on a task that is highly sensitive to disturbances in hippocampal functioning. Our results thus underscore a general inconsistency between behavioral evidence and the hypothesis that some of the cognitive effects of inescapable shock are mediated by altered hippocampal functioning.

A caveat should be noted. It has been argued that place learning depends on the induction of LTP in the hippocampus (Morris, 1989; Morris, Anderson, Lynch, \& Baudry, 1986). If inescapable shock blocks the induction of LTP in the hippocampus (Foy et al., 1990; Foy et al., 1987; Shors et al., 1989), one might expect it also to impair place learning. Consequently, the present results might be taken as evidence against the LTP-place learning hypothesis (see also Keith \& Rudy, 1990). However, it is certainly the case that multiple brain areas contribute to the control of place learning. As such, performance in a place-learning task is not a direct measure of hippocampal function. Furthermore, because we did not determine if inescapable shock blocked the induction of LTP in our animals, our data cannot be considered a strong challenge to the LTP-place learning hypothesis. Moreover, the demonstrated effects of inescapable shock on LTP were obtained in CA1; other areas where LTP occurs, such as the dentate and CA3, may not be affected.

What can be said with more certainty, however, is that the stressor treatments employed in our work are effective in producing behavioral changes in a variety of tasks that assess cognitive performance (e.g., Jackson et al., 1980; Lee \& Maier, 1988; Minor et al., 1984; Rosellini et al., 1982). Because our results strongly suggest that hippocampus-dependent cognitive processes are relatively unaffected by inescapable shock, they serve to caution against attributing the known cognitive effects of inescapable shock to impaired hippocampal functioning. 


\section{REFERENCES}

Anisman, H., \& SkLaR, L. S. (1979). Catecholamine depletion in mice upon reexposure to stress: Mediation of the escape deficits produced by inescapable shock. Journal of Comparative \& Physiological Psychology, 93, 610-625.

BarNes, C. A. (1988). Spatial learning and memory processes: The search for their neurobiological mechanisms in the rat. Trends in Neurosciences, 11, 163-169.

Drugan, R. C., Maier, S. F. (1983). Analgesic and opioid involvement in shock elicited activity and escape deficits produced by inescapable shock. Leaming \& Motivation, 14, 30-47.

Elmes, D. G., Jarrard, L. E., \& Swart, P. D. (1975). Helplessness in hippocampectomized rats: Response perseveration? Physiological Psychology, 3, 51-55.

Foy, M. R., Foy, J. G., Levine, S., Thompson, R. F. (1990). Manipulation of pituitary-adrenal activity affects neural plasticity in the hippocampus. Psychological Science, 1, 201-204.

Foy, M. R., Stanton, M. E., Levine, S., \& Thompson, R. F. (1987). Behavioral stress impairs long-term potentiation in rodent hippocampus. Behavioral \& Neural Biology, 48, 138-149.

JaCkSON, R. L., AleXander, J. H., \& Maier, S. F. (1980). Learned helplessness, inactivity, and associative deficits: Effects of inescapable shock on response choice escape learning. Journal of Experimental Psychology: Animal Behavior Processes, 6, 1-20.

KeITH, J. R., \& RUDY, J. W. (1990). Why NMDA-receptor-dependent long-term potentiation may not be a mechanism of learning and memory: Reappraisal of the NMDA-receptor blockade strategy. Psychobiology, 18, 251-257.

LEE, R. K. K., MAIER, S. F. (1988). Inescapable shock and attention to internal versus external cues in a water discrimination escape task. Joumal of Experimental Psychology: Animal Behavior Processes, 14, 302-310

LESHNER, A. I., \& SEGAL, M. (1979). Fornix transection blocks "learned helplessness" in rats. Behavioral \& Neural Biology, 26, 497-501.

MAIER, S. F. (1990). Role of fear in mediating shuttle escape learning deficit produced by inescapable shock. Journal of Experimental Psychology: Animal Behavior Processes, 16, 137-149.

Maier, S. F., Albin, R. W., \& Testa, T. J. (1973). Failure to learn to escape in rats previously exposed to inescapable shock depends on the nature of the escape response. Journal of Comparative \& Physiological Psychology, 85, 581-592.

MaIER, S. F., JACKson, R. L., \& Tomie, A. (1987). Potentiation, overshadowing, and prior exposure to inescapable shock. Journal of Experimental Psychology: Animal Behavior Processes, 13, 260-270.

Maier, S. F., Ryan, S. M., Barksdale, C. M., Kalin, N. H. (1986). Stressor controllability and the pituitary-adrenal system. Behavioral Neuroscience, 100, 669-674.

NcNaughton, B. L., Barnes, C. A., Rao, G., Baldwin, J., \& RasMUSSEN, M. (1986). Long-term enhancement of hippocampal synaptic transmission and the acquisition of spatial information. Journal of Neuroscience, 6, 563-571.

MinOR, T. R., JACKSON, R. L., \& MAIER, S. F. (1984). Effects of taskirrelevant cues and reinforcement delay on choice-escape learning following inescapable shock: Evidence for a deficit in selective attention. Joumal of Experimental Psychology: Animal Behavior Processes, 10, 543-556.

MorRIs, R. G. (1981). Spatial localisation does not depend upon the presence of local cues. Learning \& Motivation, 12, 239-260.

MorRIs, R. G. (1989). Synaptic plasticity and leaming: Selective impairment of learning in rats and blockade of long-term potentiation in vivo by the $N$-methyl-D-aspartate receptor antagonist AP5. Journal of Neuroscience, 9, 3040-3057.

Morris, R. G., ANDERSON, E., LYNCH, G. S., \& BAUDRY, M. (1986). Selective impairment of learning and blockade of long-term potentiation by an $N$-methyl-D-aspartate receptor antagonist, AP5. Nature, 319, 774-776.

Morris, R. G., Garrud, P., Rawlins, J. N. P., \& O'KeEFe, J. (1982). Place navigation impaired in rats with hippocampal lesions. Nature, 297, 681-683.

O'KeEFE, J., \& NADEL, L. (1978). The hippocampus as a cognitive map. Oxford: Oxford University Press.
Overmier, J. B., \&eligman, M. E. P. (1967). Effects of inescapable shock upon subsequent escape and avoidance behavior. Journal of Comparative \& Physiological Psychology, 63, 23-33.

Petty, F., \& Sherman, A. D. (1981). GABAergic modulation of learned helplessness. Pharmacology, Biochemistry \& Behavior, 15, 567-570.

Prince, C. R., Collins, C., \& ANisman, H. (1986). Stressor-provoked response patterns in a swim task: Modification by diazepam. Pharmacology, Biochemistry \& Behavior, 24, 323-328.

Rosellinı, R. A. (1978). Inescapable shock interferes with the acquisition of a free appetitive operant. Animal Learning \& Behavior, 6 , 155-159.

Rosellini, R. A., DeCola, J. P., Plonsky, M., Warren, D. A., \& Stilman, A. J. (1984). Uncontrollable shock proactively increases sensitivity to response-reinforcer independence in rats. Journal of $E x$ perimental Psychology: Animal Behavior Processes, 10, 346-359.

Rosellini, R. A., DeCola, J. P., \& Shapiro, N. (1982). The crossmotivational effects of inescapable shock are associative in nature. Journal of Experimental Psychology: Animal Behavior Processes, 8, 376-388.

Sherman, A. D., Allers, G. L., Petty, F., \& Henn, F. A. (1979). A neuropharmacologically relevant animal model of depression. Neuropharmacology, 18, 891-893.

Sherman, A. D., \& PetTy, F. (1980). Neurochemical basis of the action of antidepressants on learned helplessness. Behavioral \& Neural Biology, 30, 119-134.

Shors, T. J., Steib, T. B., Levine, S., \& Thompson, R. F. (1989). Inescapable versus escapable shock modulates long-term potentiation in the rat hippocampus. Science, 244, 224-226.

Sutherland, R. J., \& RudY, J. W. (1988). Place learning in the Morris place navigation task is impaired by damage to the hippocampal formation even if the temporal demands are reduced. Psychobiology, 16, 157-163.

Sutherland, R. J., \& Rudy, J. W. (1989). Configural association theory: The role of the hippocampal formation in learning, memory, and amnesia. Psychobiology, 17, 129-144.

Sutherland, R. J., Wishaw, I. Q., \& KolB, B. (1983). A behavioral analysis of spatial localization following electrolytic, kainate, or colchicine-induced damage to the hippocampal formation in the rat. Behavioral Brain Research, 7, 133-153.

Szostak, C., \& ANISMAN, H. (1985). Stimulus perseveration in a water maze following exposure to controllable and uncontrollable shock. Behavioral \& Neural Biology, 43, 178-198.

Warren, D. A., Roseluni, R. A., \& Maier, S. F. (1989). Fear, stimulus feedback, and stressor controllability. In G. H. Bower (Ed.), The psychology of learning and motivation (Vol. 24, pp. 167-207). New York: Academic Press.

Warren, D. A., Rosellini, R. A., Plonsky, M., \& DeCola, J. P. (1985). Learned helplessness and immunization: Sensitivity to response-reinforcer independence in immunized rats. Journal of $E x$ perimental Psychology: Animal Behavior Processes, 11, 576-590.

Weiss, J. M., Goodman, P. A., Losito, B. G., Corrigan, S., Charry, J. M., \&AILEY, W. H. (1981). Behavioral depression produced by an uncontrollable stressor: Relationship to norepinephrine, dopamine, and serotonin levels in various regions of the rat brain. Brain Research Reviews, 3, 167-205.

Williams, J. L. (1987). Influence of conspecific stress odors and shock controllability on conditioned defensive burying. Animal Learning \& Behavior, 15, 333-341.

Williams, J. L., \& LiERLE, D. M. (1986). Effects of stress controllability, immunization, and therapy on the subsequent defeat of colony intruders. Animal Learning \& Behavior, 14, 305-314.

Woodmansee, W. W., Desan, P. H., Silbert, L. H., Smock, T. K., \& MAIER, S. F. (1988, November). Post-stress changes in rat brain monoamines and their free and conjugated metabolites using HPLC with serial oxidative-reductive electrochemical detection. Paper presented at the meeting of the Society for Neuroscience, Toronto.

(Manuscript received August 6, 1990; revision accepted for publication November 12, 1990.) 